\title{
Práticas docentes em construção: considerações sobre performances e identidades de professores no espaço escolar
}

\author{
Samuel Douglas Farias Costa $^{1}$
}

Resumo: A construção da professoralidade envolve o desempenho de práticas específicas relacionadas ao campo profissional da docência. Por outro lado, as subjetividades, trajetórias, histórias de vida, entre outras características particulares, são diacríticos na construção dessas práticas. Também não podemos desconsiderar os contextos educacionais e as configurações escolares, nas quais os sujeitos estão inseridos. Todos esses elementos são relevantes para entendermos a construção de identidades e performances docentes. A proposta deste artigo é refletir sobre esse processo a partir de experiência de estágio docente ao longo de 2011 e 2012. Utilizo técnicas de observação no espaço escolar, com foco, sobretudo, na figura do professor de sociologia, entrevistas com professores e relatos autobiográficos. O resultado se mostra profícuo para pensar alguns elementos gerais e particulares da construção da professoralidade, especificamente no campo do ensino de sociologia.

Palavras-chave: práticas docentes; performance; identidade professoral; professoralidade.

${ }^{1}$ Licenciado e bacharelando em Ciências Sociais pela Universidade Estadual de Maringá (UEM). 


\begin{abstract}
The construction of professorality involves the performance of specific practices related to the professional field of teaching. On the other hand, subjectivities, trajectories, life histories, among other characteristics, are diacritics in the construction of these practices. Nor can we ignore the educational contexts and educational settings in which subjects are embedded. All these elements are relevant for understanding the construction of identities and teaching performances. The purpose of this article is to reflect on this process from a teaching internship experience throughout 2011 and 2012. I use observation techniques at school, focusing mainly on the figure of sociology professor, interviews with teachers and autobiographical accounts. The result proved itself fruitful to think some elements of general and particulars of the construction of professorality, specifically in the field of teaching sociology.
\end{abstract}

Keywords: teaching practices; performance; professorial identity; professorality.

\title{
Introdução
}

No ano de 2011, em Estágio Supervisionado I, realizei atividades que propunham pensar o espaço escolar e suas dinâmicas específicas. No decorrer de 2012, em Estágio Supervisionado II, mudei o foco para a prática docente e pude atentar para as estratégias de atuação de professores dentro de contextos escolares empíricos. A proposta deste artigo é reunir reflexões possíveis a partir de minha experiência de estágio docente, ao longo da graduação em ciências sociais na Universidade Estadual de Maringá (UEM), e problematizar a 
construção das identidades e performances docentes, inclusive a minha de pesquisador/autor neste artigo. A metodologia é composta por diferentes técnicas de pesquisa que foram empregadas ao longo destes dois anos, que expressam um caráter experimental deste trabalho. Utilizei entrevistas, observação participante e também relatos autobiográficos ${ }^{2}$.

De 2011 a 2012 realizei observações frequentes e sistemáticas em um colégio estadual da cidade de Sarandi (PR), cidade localizada na região metropolitana de Maringá (PR), que resultaram em dados de base para a compreensão específica das configurações de um dado espaço escolar. No primeiro semestre de 2012, junto a um grupo de alunos, realizei entrevistas com uma professora e um professor do ensino básico, ela de sociologia e ele de história. Aqui, a intenção era perceber a iniciação da prática docente a partir de experiências distintas.

A minha própria experiência como professor/estagiário também é levada em consideração. Como atividade final de cada um dos períodos de estágio, apliquei regências na escola. A experiência é interessante para perceber a minha própria construção de professoralidade. Os temas abordados, os materiais utilizados e os métodos didáticos empregados, estão relacionados à construção da

\footnotetext{
${ }^{2}$ Aqui, vale destacar a inspiração no método (auto) biográfico, discutido por autores como Franco Ferrarotti (2010) e António Nóvoa (1995, 2010).
} 
minha identidade professoral. Cada atuação docente tem as suas próprias características, proponho, além de relatar algumas estratégias de professores, pensar as questões que influenciam nessas distintas performances $^{3}$ em sala de aula, sobretudo, aplicadas ao ensino de sociologia no ensino médio.

\section{O professor de sociologia no ensino médio}

A institucionalização da sociologia no Brasil, como disciplina na escola média, remete a um histórico de constante instabilidade. Segundo Simone Meucci (2000), a sociologia esteve presente na escola pouco antes da instituição dos primeiros cursos de graduação em ciências sociais nas universidades brasileiras (década de 1930), portanto, os intelectuais nacionais que primeiro pensaram e ajudaram na construção da disciplina não eram sociólogos, a maior parte tinha formação em direito. Isso não resultou em um desvinculo entre a sociologia e a ciência, porém, a disciplina estava fortemente influenciada pelo pensamento positivista. Segundo a autora, esses primeiros intelectuais se agarraram à ideia de formação de uma nação.

\footnotetext{
${ }^{3}$ Por performances, entendem-se as atuações, dramatizações, ritos, práticas e papéis desempenhados em diversos contextos e situações socioculturais, ver Victor Turner (1987,2005, 2008), Richard Schechner (1985, 2003, 2011) e Erving Goffman (1985), entre outros.
} 
Entendia-se que eles seriam os atores privilegiados na transformação do país e o conhecimento sociológico era visto como um instrumento oportuno para a construção de uma "nova nação".

Nesse contexto histórico, na aplicação prática dentro de salas de aula, a sociologia estava ligada a questões como reajustamento social, trabalho, saúde pública, comunidades rurais e urbanas e até mesmo higiene. A disciplina era entendida como algo relacionado à moral e à construção de cidadãos comprometidos com o futuro do país. Era "uma obrigação cívica reconhecer e solidarizar-se com os problemas do país e, sobretudo, crer nas leis sociológicas que nos garantiam um futuro melhor" (MEUCCI, 2000, p.67).

A inconstante presença da disciplina nas grades escolares ao longo do século XX e início do XXI, mais esse histórico de influências positivistas, entre outras questões, influenciaram na conjuntura do contexto contemporâneo no qual a sociologia no ensino médio ainda não se apresenta como um campo consolidado. Ainda há muito que discutir sobre os métodos, temas e conceitos a serem abordados, entre outras pautas que os professores se deparam. Qual sociologia trabalhar no ensino médio? Como traduzir o conhecimento acadêmico para o ensino básico? Como construir um currículo adequado às especificidades dos alunos? Quais conteúdos devem integrar este currículo? Enfim, essas e outras questões são enfrentadas pelos 
profissionais da área diariamente.

Alguns autores (CARNIEL, 2012; GOODSON, 2008; PERALVA \& SPOSITO, 1997) mostram como a perspectiva que os professores possuem da prática docente, geralmente, difere significativamente antes e depois de suas atuações. A estrutura e cultura escolar e as experiências subjetivas, são elementos importantes para compreensão das práticas nesse cenário. Nesse sentido, é relevante percebermos e analisarmos as estratégias de atuação desenvolvidas por docentes dentro de sala de aula. Hierarquias e construções simbólicas diversas permeiam as negociações entre docentes, alunos, coordenação pedagógica, direção, etc.

\section{Dois exemplos bons para pensar as identidades professorais}

A prática docente envolve uma iniciação no espaço escolar. Neste subtítulo proponho explorar esse elemento em duas entrevistas com professores do ensino básico da rede pública da cidade de Maringá (PR). O roteiro das perguntas foi semi-estruturado, portanto, permitiu que a entrevistada e o entrevistado discorressem sobre os assuntos propostos sem muitas restrições e com possíveis digressões. Os dois casos e a comparação dos mesmos, com ênfase na disciplina de sociologia, se mostram profícuos para pensar a construção de 
professoralidades e nos proporcionam apresentar alguns pressupostos teóricos para este artigo.

A primeira entrevista realizada foi com uma professora de sociologia. Ao ser questionada se as aulas de sociologia no ensino médio eram como ela imaginava ela responde:

Não, de jeito nenhum. São dois pontos, primeiro que quando você está na academia e vem para o estágio, dependendo da escola que você vai você leva um choque incrível com a "molecada", aquele barulho, uma pessoa pra dar conta de uma turma de 40 alunos, parece que nada está sendo compreendido, e que a pessoa está falando para parede, paras lâmpadas, e nada vai surtir efeito. Então a experiência do estágio de observação é uma única regência, pra mim foi muito decepcionante, porque está muito longe dessa perspectiva de como vai ser você na sala com 40 alunos. A experiência de estágio me passou isso, de que era um caos o ensino, a educação, o ensino médio, a turma dos adolescentes, totalmente fora da realidade. E o outro pensamento é [...] que a sociologia está ali, disciplina de contestação, de critica, é legal, os adolescentes vão gostar, vão perguntar e vão questionar, também passava isso pela minha cabeça, mas quando você vem pra sala de aula é totalmente diferente, os alunos não sabem o que é isso e nem querem saber, a grande maioria pelo menos.

Percebemos na fala dela que houve em sua experiência uma 
ruptura entre seus conhecimentos e expectativas de acadêmica e a realidade do ensino médio. Podemos dizer que há um desconhecimento da cultura escolar e das dinâmicas que a mesma envolve. A entrevistada ainda diz que

[...] é um choque de realidade [...]. O primeiro ano pra mim foi $[\ldots]$ de desencantamento total com o ensino, com as escolas, com as políticas. [...] $\mathrm{Na}$ prática a gente vai querer modificar isso, mas não conseguimos modificar, você tem que se adequar, e a única coisa que a gente não quer é se adequar, a gente quer agir de outra forma e não consegue, às vezes muito pouco. [...] Dentro da sala de aula o domínio é teu, eu faço meu espaço, então foi nessa perspectiva de que foi uma escolha, é uma opção e eu quero tentar o quanto eu puder, enquanto eu tiver forças pra isso, eu vou tentar.

A docente se refere às condições que estão postas ao professor, que dizem respeito às políticas públicas educacionais, à estrutura da escola e à cultura escolar, o modo de pensar e agir dos atores desse cenário. Ela destaca também os limites e as possibilidades de criar estratégias para transitar nesse contexto. Para fins de comparação, apresento o segundo entrevistado, que foi um professor de história. $\mathrm{Na}$ mesma perspectiva, de um choque cultural, ele afirma que

[...] não tinha ainda os quesitos suficientes pra 22 
administrar uma aula, por exemplo, sofri muito no começo, por que você não recebe uma instrução, nem na universidade nem no próprio colégio, de um estatuto, de uma metodologia de aula. Você vai e é jogado, principalmente o PSS, e lá você tem que desenvolver o seu método e vê aquilo que se assemelha ao aluno em sala, o que pra ele será importante, como você vai traduzir esse conhecimento, no caso da história, o conhecimento histórico. Mas, houve uma grande dificuldade no inicio sem dúvida alguma. E acho que ainda tenho, mas a gente vai superando isso.

$\mathrm{Na}$ fala de ambos é possível notar um processo de estranhamento com esses "outros" - os alunos, os demais atores do cenário escolar e a sua lógica própria. O desenvolvimento de alguma prática só é possível depois de certa aproximação e familiarização com essa cultura escolar. Como coloca Carniel (2012), aos poucos se afigura no docente recém-chegado a imagem de um professor, o ritual se repete até que deixamos de estranhá-lo. "A escola, como instituição social, é um local carregado de sistemas simbólicos, por ser um espaço privilegiado de trocas simbólicas, de criação e reprodução de mensagens, de gestos e linguagens" (STANO, 2001, p. 41). Sendo assim, é preciso, de alguma forma, se aproximar desses sistemas.

A professora entrevistada diz que seu método é pautado no diálogo, discussões e debates, e que no primeiro dia de aula ela pede que seus alunos escrevam histórias de vida sobre si próprios. Para ela, é 
importante conhecer a linguagem cultural e experiências vivenciadas pelos seus alunos, só assim a comunicação pode ser estabelecida com melhores resultados. Nesse sentido, a professora afirma que sempre trazia vídeos e clips de músicas que considerava chamar a atenção dos alunos e/ou com os quais eles poderiam se identificar. Essa era também uma estratégia de controle, geralmente, ela passava esses vídeos nos minutos finais das aulas, o que fazia com que os alunos bagunçassem menos e não ficassem conversando ou andando pela sala. Percebe-se que a bagunça, a constante conversa, o barulho em geral, uso de tecnologias (celulares, mp4, etc.), entre outros elementos, são aspectos dessa cultura escolar e juvenil. Os professores precisam desenvolver estratégias para atuar e transitar nesse espaço cultural, isso pode envolver tanto o diálogo, quanto estratégias de controle.

$\mathrm{Na}$ entrevista com o professor de História, ele afirma:

Eu sofri muito no começo. Uma [...] questão [...] foi a divisão da História, como ela é colocada, é um método positivista na História. Quando eu peguei os livros, que são minha referência, lembrando que minha relação com eles é através do livro didático, você pegava aquele método positivista que estava no livro... sofria muito... porque, sabe aquela coisa História Antiga, Medieval, Moderna e Contemporânea e todos aqueles exemplos, os fatos históricos? Isso se perdia um pouco porque, no mestrado principalmente, eu aprendi justamente a 
ideia de romper com isto, de romper com o Positivismo. Há um novo tipo de leitura, novo tipo de entendimento da História. [...] A nova História foi uma crítica diferente à tudo isso. Isso eu sofri muito, mas com o tempo, o trabalho, você vai assimilando e desenvolvendo um novo tipo de trabalho, leva material novo pra eles, material extra, aí você vai conseguindo desenvolver um trabalho, mas no começo é frustrante sem dúvida alguma.

É evidente que, mesmo com estruturas objetivas que estão postas a priori da ação do professor, as estratégias para desenvolver métodos e práticas são diversas. Nesse sentido, o espaço escolar é dinâmico e está em constante construção, da mesma forma acorre com as identidades dos professores. "Identidades não devem ser consideradas cristalizações de modo de ser, mas é necessário vê-las como resultantes de negociações entre sujeitos co-partícipes do mesmo espaço-tempo profissional" (STANO, 2001, p. 42).

Ao comparar a experiência da professora de sociologia e do professor de história sobre as suas inserções no espaço escolar, podemos dizer que, a princípio, há um desconhecimento dos professores com a realidade escolar e suas expectativas geralmente divergem das condições reais de atuação. Isso se apresenta como uma característica comum. No entanto, para a sociologia há um campo mais amplo de possibilidades, visto que a disciplina possui um histórico de 
instabilidade no ensino público obrigatório e as bases curriculares estão em constantes discussões e revisões. Ao contrário, a disciplina de História, mesmo pautada em bases positivistas, possui referências mais institucionalizadas para o professor, embora as mesmas possam ser extrapoladas. Nesse sentido, a construção da professoralidade depende essencialmente de características subjetivas de cada professor.

Assim, o processo de construção de uma identidade profissional está inserido num arranjo amplo de mundos vividos e processados subjetivamente, no caso pelos/as professores/as em questão. Ou seja, a escola é um espaço na conformação e estruturação de um modo de ser-estar professor, que resulta de tensões e contradições internas ao âmbito do exercício profissional e social (STANO, 2001, p. $38)$.

Como Stano (2001), entendo que o espaço escolar é fluído, sendo assim, permite rupturas e estratégias diversas de atuação. Isso resulta que a construção desse espaço é constante. As identidades dos professores, que estão ligadas às suas práticas, atuações e performances, dizem respeito aos diálogos e negociações com os diversos atores que permeiam esse espaço escolar. Percebe-se que as práticas docentes no ensino médio estão diretamente vinculadas às formações acadêmicas dos professores, suas ideologias, trajetórias de vida, entre outras 
características e experiências que compõem suas subjetividades.

\section{A minha iniciação: um estranho familiar}

Entre os anos de 2005 e 2007 fui aluno em um colégio com nome de poetisa na cidade de Sarandi. $8^{\mathrm{a}}$ ano do ensino fundamental (atualmente $9^{\circ}$ ano), $1^{\mathrm{a}}$ ano do ensino médio e metade do $2^{\circ}$ ano foram as séries que cursei nesta instituição escolar. Nos anos de 2011 e 2012 retornei ao local, não mais como aluno, mas como estagiário de professor de sociologia. Por coincidência, foi lá também que tive meus primeiro contato com a disciplina.

As aulas de sociologia que tive nas manhãs de 2006 foram como setas que me mostraram um caminho para as ciências sociais. A professora que ministrava essas aulas era recém-formada na área específica da disciplina pela UEM e aspirante na docência. Em minha mente, as suas aulas eram uma ruptura em comparação a dos outros professores. As imagens que tenho são de uma mulher que questionava os alunos, que colocava em cheque nossos preconceitos mais naturalizados, carregava uma pitada de radicalismo e acidez em seu discurso - sua performance docente me cativava.

Nesse tempo, construí a imagem de uma sociologia meio "radical", meio "do contra", meio "liberal", meio "libertária" e meio 
outras coisas que eu não sabia direito o que eram. Enxergava-a como um bom caminho para tentar explicar o turbilhão de dúvidas e crises pelas quais passamos na adolescência e juventude. Passei a enxergar a sociologia como uma mitologia pela qual eu poderia explicar meu mundo, um universo de crenças das quais eu ainda pouco conhecia. Muito disso mudaria nos próximos anos.

Foi lá neste colégio que tive o primeiro contato com aquele estranho que era a sociologia. De alguma forma me identifiquei e investi na construção de uma identidade social e profissional. Eu queria ser professor de sociologia. Atualmente, com outra perspectiva da disciplina, mas ainda com resquícios daquela que criei aos 15 anos, retornei ao colégio com uma nova proposta de atuação. Uma nova experiência nesse lugar tão próximo e conhecido, mas, ao mesmo tempo, diferente e transformado. Nossas ações são guiadas por crenças, mitologias, ideologias, ideais, utopias, enfim, nossas formas de pensar estão em constante diálogo com nossas ações. Ambas estão ligadas as questões com as quais nos identificamos. Escolher este colégio como palco de minha iniciação na vida docente não foi uma eleição ao acaso.

\section{Conhecendo o espaço escolar: um panorama geral do colégio}

A atual configuração do colégio, no qual fui estagiário, combina 
certa rigidez de padrões e normas, com o que poderíamos chamar de uma espécie de liberdade permitida. Com isso quero dizer que os alunos podem usufruir de relativa abertura se seguirem as regras de base. Essa liberdade permitida diz respeito, por exemplo, a permissões para sair da sala para ensaiar apresentações, frequentes passeios promovidos pela escola e participação em eventos extracotidianos, como festa das nações, feira de ciências, semana da consciência negra, campeonatos esportivos, etc.

Dentre os principais aspectos rígidos do colégio está à própria estrutura física. Ele é todo cercado por grades e arame farpado para evitar a entrada e saída do ambiente escolar sem que seja mediada pela administração da escola. Dos alunos é exigido o uso de uniforme e para não-alunos, como pais e outros responsáveis, é necessário que usem o interfone para se comunicarem com a secretária, para depois terem a entrada permitida ou negada. Estagiários, professores e outros funcionários não possuem um uniforme específico, mas precisam ser identificados antes de entrarem. Para de fato adentrar no colégio é preciso passar por dois portões. Há um único bloco de salas de aulas, com térreo e primeiro andar, a entrada no mesmo não é permitida durante o intervalo. A parte de trás desse bloco é cercada por grades, o que impede os alunos de terem acesso a um espaço vazio do terreno do colégio. 
No geral o colégio é um local repleto de trancas, fechaduras e cadeados. Para além da segurança necessária, é evidente a função de coerção que toda essa estrutura possui. A ideia de panopticon (FOUCAULT, 1985) aqui é aplicável. A estrutura da escola é planejada de tal forma que os alunos fiquem "à vista". As regras e normas seguem a mesma lógica: controle e disciplina. Para sair da sala de aula é preciso um cartão de autorização do professor que e só é fornecido a um aluno de cada turma por vez. A não ser em algumas exceções, como quando o diretor ou alguma pedagoga chama alguém para conversar. Nesse caso a convocação é feita por um sistema de interfone que há instalado entre a secretaria e cada uma das salas de aula. Ainda, outros elementos nos remetem à disciplina e coerção, como, por exemplo, uma clássica e viva herança do ensino militarista que é o ritual cívico no qual se entoa o hino nacional, evento realizado uma ou duas vezes na semana antes da primeira aula.

A configuração das salas de aula também é marcada por estratégias de controle, organizada com as clássicas fileiras em oposição à mesa do professor e pelo espelho de sala. Este é um documento que define em que lugar cada aluno tem a obrigação de se sentar durante todo o ano. Esse espelho da sala é construído no começo do ano letivo pelo professor monitor e o aluno eleito o líder da turma.

Portanto, há certa rigidez, mas precisamos considerar que regras 
e normas muitas vezes são burladas, subvertidas ou simplesmente ignoradas. É preciso levar em conta que pessoas estão inseridas nesse aparato e, dessa forma, o funcionamento da escola envolve diversos atores e suas lógicas próprias que, em certa medida, se aproximam ou distanciam do que é normatizado.

Para começar, frequentemente, os alunos chegam atrasados. As salas de aula começam com fileiras na primeira aula e terminam em um emaranhado de carteiras dispostas de formas diversas até a quinta aula. A grande maioria dos alunos não segue o espelho da sala e possuem uma lógica própria de escolha de lugares, a qual todos respeitam dentro de sala. É preciso levar em consideração a atuações dos alunos, professores, funcionários e os demais atores dentro desse ambiente, como indivíduos formadores do espaço escolar.

O acesso à escola é mediado mais por relações de proximidade, como amizade, do que pela utilização do uniforme. O que pode ser, inclusive, entendido como mais seguro. Pois, nesse caso, só entra quem de fato se conhece, sabe que é aluno ou aluna, responsável, funcionário, enfim, não basta ter um uniforme do colégio para entrar. É claro, que essa lógica pode falhar e um estranho com o uniforme conseguir acesso ao colégio, mas a lógica da proximidade e do reconhecimento é predominante a oficial. Algumas vezes, fui ao colégio fora do horário do estágio - para tirar fotocópias ou buscar algum documento - e a 
senhora que cuida da portaria - que conheço desde a época que eu estudava lá - nem perguntava o que eu havia ido fazer, apenas abria o portão e me cumprimentava.

Ainda, há de se mencionar que o ritual cívico do Hino Nacional é um fracasso dentro de suas expectativas formais. Geralmente, ocorre na primeira aula, assim que os alunos chegam à suas respectivas salas. $\mathrm{O}$ diretor, ou alguma das pedagogas, anuncia pelo interfone para que todos se coloquem em posição de sentido para cantar. O hino é tocado pelo interfone e o que os alunos fazem apenas é ficarem em pé - às vezes, nem todos. Na maioria das vezes, os discentes conversavam durante o hino, se escoravam nas carteiras e nas paredes, faziam piadinhas, não tiravam os bonés, cochichavam, mexiam no celular, dentre outras coisas. Certa vez, alguns garotos faziam "piadinhas" e riam quando um deles soltou em voz alta as palavras "Heil Hitler!". O ocorrido mostra, no mínimo, a ironia, o descrédito e a rejeição de alguns alunos para com o ritual. Do professor que acompanhei, lembro-me de escutá-lo reclamar que o Hino Nacional sempre tocava na aula dele. Era mais uma expressão de inconformidade com essa prática do que uma afirmação literal, já que em cada uma das outras turmas do colégio havia outro professor na mesma situação.

No mês de novembro, o Hino à Bandeira do Brasil também era tocado. Esses eventos tinham um caráter autoritário, percebia-se que 
nem os alunos e nem os professores estava interessados em participar. Concretizava-se ali um mito do discurso nacional. Em outro desses rituais, com alunos, professores e demais funcionários reunidos no pátio do colégio, presenciei uma situação na qual uma pedagoga penalizava os professores verbalmente por meio do sistema de som do colégio. Culpava-os por não conseguirem manter os alunos em postura cívica e organizados para o ritual. Frente aos alunos, os docentes ficaram constrangidos como o ocorrido. Ao colocar o hino para tocar, a caixa de som falhou e o que ouvíamos era um barulho chiado e incomodo. $\mathrm{O}$ teatro todo foi por água abaixo.

Outra situação recorrente é os alunos saírem da sala em duplas ou em trios. Muitas vezes dizem ao professor que vão para um lugar e acabam indo para outro. Mas não demoram muito a voltar já que a escola é pequena e os espaços de acesso aos alunos são poucos.

Um elemento bastante interessante é que não se toca nenhum tipo de sinal entre as trocas de professores, mas apenas na entrada, no intervalo e na saída. Dessa forma, quando chega o momento preestabelecido, cada professor deve encerrar a aula e trocar de sala por conta própria. Tal método gera menos bagunça e possibilita ao professor finalizar a aula, até mesmo com negociações de tempo com outros professores, sem que o barulho do sinal atrapalhe que ele feche um pensamento ou um assunto. 
Juntar tanto os aspectos formais quanto a atuação prática de todos esses atores pode nos dar uma visão mais próxima do que seria realmente a cultura escolar. Segundo Julia,

[...] poder-se-ia descrever a cultura escolar como um conjunto de normas que definem conhecimentos a ensinar e condutas a inculcar, e um conjunto de práticas que permitem a transmissão desses conhecimentos e a incorporação desses comportamentos; normas e práticas coordenadas a finalidades que podem variar segundo as épocas (finalidades religiosas, sociopolíticas ou simplesmente de socialização). Normas e práticas não podem ser analisadas sem se levar em conta $o$ corpo profissional dos agentes que são chamados a obedecer a essas ordens e, portanto, a utilizar dispositivos pedagógicos encarregados de facilitar sua aplicação, a saber, os professores primários e os demais professores. Mas, para além dos limites da escola, pode-se buscar identificar em um sentido mais amplo, modos de pensar e de agir largamente difundidos no interior de nossas sociedades, modos que não concebem a aquisição de conhecimentos e de habilidades senão por intermédio de processos formais de escolarização: aqui se encontra a escalada dos dispositivos propostos pela schooled society que seria preciso analisar; nova religião com seus mitos e ritos contra a qual Ivan Illich se levantou, com vigor, há mais de vinte anos. Enfim, por cultura escolar é conveniente compreender também, quando é possível, as culturas infantis (no sentido antropológico do termo), que se desenvolvem nos pátios de recreio e o afastamento que apresentam em 
relação às culturas familiares. (JULIA, 2001, p. 1011)

Portanto, a cultura escolar abrange mais do que as regras formais e as práticas, mas também o processo de transmissão e socialização do conhecimento. Vejamos como isso se configura nas aulas de sociologia e como o professor da disciplina constrói e desempenha sua prática docente.

\section{Observando o professor e a rotina escolar: questões gerais}

Ao longo de 2011 e 1012 acompanhei o mesmo professor de sociologia, que, para fins deste artigo, dou o pseudônimo de Carlos. Frequentei diferentes turmas de $1^{\mathrm{a}}, 2^{\mathrm{a}}$ e $3^{\mathrm{a}}$ séries do ensino médio. A oportunidade de estar nas três séries foi frutífera dentro da proposta de minha observação, que era compreender alguns aspectos da prática docente. Por um lado, eu não acompanhei a trajetória de uma turma e a dinâmica desses alunos, mas como o meu foco era o professor dentro do espaço escolar, penso que foi mais rico perceber como era a sua performance dentro de turmas distintas e lidando com temas assuntos distintos.

Geralmente, eu e Carlos chegávamos juntos na sala de aula. Encontrávamos-nos por volta das 07h30min na sala dos professores e 
descíamos para o bloco de aula conversando. Em sala, geralmente, eu me sentava em uma carteira próximo aos alunos e ficava fazendo anotações em meu caderno de campo. Os primeiros minutos da aula sempre eram destinados à chamada e, às vezes, ao ritual cívico do Hino Nacional.

O tempo da aula é uma questão importante ${ }^{4}$. Pelo que percebi do professor que acompanhei, ele busca repetir uma performance similar em cada sala de aula, calculada e esquematizada, para controlar a questão do tempo. Porém, na prática as coisas fogem da ordem prevista. Algo que atrapalha esse ritmo na primeira aula é a chegada atrasada dos alunos. O professor deixa de começar a aula para "dar um tempo" até os alunos chegarem.

Ao iniciar a aula, Carlos tinha o hábito de escrever um enunciado ou conteúdo na lousa, como por exemplo, Formação do Estado Brasileiro ou Direitos e Cidadania. Na maioria das vezes ele utilizava o livro didático Sociologia para o Ensino Médio, de Nelson

\footnotetext{
${ }^{4}$ Vale destacar aqui que, na perspectiva de Victor Turner $(1987,2005,2008)$ e Richard Schechner $(1985,2003,2011)$, a performance pode ser compreendida como um rito ou evento ritual extracotidiano, ensaiado e temporal. Essa visão difere daquela que entende a performance como uma dramatização cotidiana, como a abordagem interacionista de Erving Goffman (1985). No entanto, existem também tentativas de unir essas duas perspectivas, como a de John Dawsey (1999, 2005), que entende que extracotidiano e cotidiano não são completamente opostos e excludentes, em sua pesquisa etnográfica, este autor constata que uma performance extraordinária pode compor, também, a vida cotidiana.
} 
Dacio Tomazi (2010), e pedia para que os alunos lessem textos. No geral, ela realizava algumas explanações e passava questões para serem entregues ou "vistadas" no caderno. Essa era a dinâmica que Carlos tentava manter no dia-a-dia, mas as variações da mesma eram frequentes. Ao acompanhar, por exemplo, a explicação do mesmo conteúdo em duas turmas de $2^{\circ}$ ano distintas, percebi como o professor se identificava e se envolvia muito mais com uma turma do que com a outra.

Era possível perceber, também, certa relação de amizade entre o professor e os alunos. Eles faziam "brincadeiras" uns com os outros com certa frequência. Em um dos últimos dias de aula o professor fez um slide com música, fotos dos alunos e da escola e mensagens de amizade. Nesse sentido, o professor procurava fazer algumas "piadinhas" ou tentava ser engraçado para se aproximar dos alunos, muitas vezes sem sucesso e reproduzindo alguns preconceitos. Certa vez, quando ele explicava a divisão social do trabalho em sociedades tradicionais, ele destacou a separação por gênero, "homens faziam determinado trabalho, mulheres faziam outro... quem era gay não fazia nada" (em outra turma ele usou o termo boiola). Destaco aqui que as discussões sobre gênero e sexualidade não eram muito problematizadas por Carlos e algumas de suas "piadas" tinham um caráter heteronormativo. Isso evidencia que cada professor tem proximidade 
com temas e assuntos específicos de acordo com sua formação e seus interesses, sendo assim, geralmente, atribuem maior relevância a um tema do que a outro. No caso investigado, constatou-se uma maior atenção do professor para com as relações de trabalho e as estruturas econômicas e políticas da sociedade do que com temas ligado à cultura, identidades sociais e minorias.

Além das aulas dentro deste modelo rotineiro, havia também algumas atividades e eventos extraordinários. Com certa periodicidade, o professor utilizava vídeos e filmes para dialogar com os conteúdos problematizados. Acompanhei duas turmas que assistiram ao filme Querô (2007), dirigido por Carlos Cortez, para discutir marginalidade e instituições sociais de reinserção. Também havia vários eventos nos quais se desenvolvia atividades extraclasses, tive a oportunidade de acompanhar uma Festa das Nações, uma Feira de Ciências e um evento dedicado ao Dia da Consciência Negra. Nessas situações, o professor desenvolvia atividades de caráter mais prático e lúdico com os alunos, o que era mais uma exigência da escola - devido aos eventos - do que uma proposta de Carlos.

Vez ou outra, o professor experimentava "novos" métodos para chamar a atenção dos alunos. Certa manhã ele utilizou uma cadeira para isso. Os alunos, em geral, se dispersam muito facilmente, e nesse dia, em específico, eles correram todos para a janela pra ver um balão de 
uma campanha eleitoral que voava próximo ao colégio. Eu também parei de prestar atenção no professor para observar o balão. Carlos parou de falar, chegou perto de mim e disse "É nessas horas que a cadeira é eficiente". Ele pegou uma cadeira enquanto os alunos olhavam pela janela e colocou com força em cima de uma carteira, batendo suas pernas contra a madeira para fazer barulho. Os alunos voltaram o olhar para ele e estranharam a situação. Um deles perguntou "Quem vai sentar aí?’. O professor começou então a explicar mais-valia usando como exemplo o processo de produção da cadeira.

A prática docente segue uma lógica própria do professor em diálogo com o contexto de cada turma e as orientações e normas do Estado e da escola. São diferentes fatores que implicam em práticas concretas. Em duas aulas específicas, acompanhei Carlos aplicar o mesmo conteúdo em duas turmas distintas. A comparação é muito interessante. O conteúdo da aula foi o mesmo em ambas, Estado no Brasil, no entanto, a performance desempenhada pelo professor difere de uma aula para a outra, essas diferenças podem ser atribuídas, sobretudo, às configurações específicas de cada aula e turma.

$\mathrm{Na}$ primeira aula o professor chegou junto comigo às 07h30minh da manhã. Havia poucos alunos e alunas, sendo assim, ficamos conversando enquanto chegavam. Não tardou para que logo a sala estivesse lotada, mas o professor ficou em dúvida se naquela terça- 
feira tocaria o Hino Nacional. Ele esperou mais um pouco, mas o hino não tocou. $\mathrm{O}$ professor tentou se aproximar dos discentes e atraí-los para a aula com conversas informais e perguntas sobre as férias, alguns poucos correspondiam. Ele parte para a chamada, na qual se vão alguns minutos. Depois, pede para dois alunos irem à biblioteca buscarem o livro didático que irão utilizar e lá se vão mais alguns minutos de espera. Nesse tempo, ele comenta com os alunos sobre a situação de alguns professores contratados pelo Processo Seletivo Simplificado (PSS) do Paraná, que estavam sendo demitidos devido ao fechamento de turmas com poucos alunos.

Após uns 20 minutos dessa "introdução rotineira", ele começa com o conteúdo propriamente dito. Ele usa a lousa apenas para escrever o enunciado do que será feito na aula e pede para os alunos lerem um texto do livro didático sobre a política brasileira. Os alunos começam a ler. Alguns terminam outros não. $\mathrm{O}$ professor interrompe com $\mathrm{o}$ argumento de que quem não terminou não precisa fazê-lo, pois já dava pra eles terem uma ideia sobre o que se tratava o texto. Para Carlos, era mais importante que eles prestassem atenção na sua explicação naquele momento. Percebo como falta tempo para Carlos poder explorar melhor o conteúdo. O professor faz uma explicação breve, dialoga com os alunos e questiona-os sobre o assunto do texto. Carlos apresenta alguns exemplos que julga conter uma dimensão prática e próxima da 
realidade dos alunos. Por exemplo, resgata uma analogia, presente no texto em questão, entre o voto em determinado partido político e a escolha do time de futebol. Com isso, discutia o que ele interpretava como uma falta de ideologias na política brasileira.

Após sua rápida explicação dialogada com os alunos, ele pede que eles respondam duas questões do livro didático e fica andando pela sala, auxiliando quem solicita. Na medida em que eles terminam, ele lê as respostas e faz um visto no caderno. Depois pede para que uma aluna recolha todos os livros e fica conversando informalmente com os discentes até o próximo professor chegar.

Na segunda aula, chegamos um pouco atrasados e tudo é mais corrido. O formato da aula é a mesma, mas algumas diferenças dizem respeito, principalmente, à configuração da turma, que poderíamos caracterizar como mais "enérgica". Os alunos dessa segunda turma são mais falantes, dispostos a saírem de seus lugares e a fazer barulho logo que começou a aula, uma aluna deu um grito quando o professor começou apagar o quadro com o conteúdo da aula do professor anterior.

Para chamar atenção para o conteúdo da aula, ele tinha que agir de maneira diferente com essa turma, e me parece que a sua estratégia foi tentar ser mais próximos deles, com paciência, provocações reflexivas e certo "humor" em seus comentários. O conteúdo era o mesmo que o da outra turma - as explicações, as 
anotações no quadro, etc. - mas a relação/interação entre professor e alunos tomava outros contornos.

\section{Prática pedagógica: experiência de regência em sala de aula}

Em 2011, quando realizava o Estágio Supervisionado I, contei para o professor Carlos sobre minha pesquisa com uma população Guarani no Paraná. A partir dessa conversa informal, ele me convidou para dar aulas sobre o tema populações indígenas para duas turmas de $3^{\text {o }}$ ano. Foi minha primeira experiência como docente durante o estágio.

Levei assuntos gerais sobre populações indígenas no Brasil, etnia, etnocentrismo, identidade étnica e mudança cultural. O que propus foi mais um debate do que uma aula expositiva. Discutimos estereótipos, políticas voltadas para as populações indígenas e contei sobre a minha pesquisa e trabalho de campo. Percebi que, provavelmente por eu ser alguém de fora, um professor "novo", eles se interessaram mais do que o comum na aula.

No ano seguinte, no final do Estágio Supervisionado II, combinei com o professor que eu daria duas aulas, também para os $3^{\circ} \mathrm{s}$ anos, mas agora sobre outro assunto. Trabalhei a temática poder $e$ política no cotidiano. Nesse caso, os recursos didáticos que utilizei foram slides com imagens, vídeo, músicas e um impresso com textos e 
charges.

Para trabalhar o tema das redes de poder e ação política no nosso cotidiano, propus aos alunos iniciarmos com o que eles conheciam sobre política. Questionei-os sobre o que eles entendiam do assunto. Partimos daquilo que eles conheciam para as noções de poder e dominação de Max Weber e depois de poder e controle de Michel Foucault (1985). Levei quatro tirinhas da série $O$ pequeno travesti, do cartunista Laerte, para discutirmos sobre o poder e controle exercido pela sociedade sobre nossos corpos e comportamentos. Dentro dessa mesma proposta, assistimos ao vídeo Era uma vez outra Maria (PROMUNDO et al., 2006), focando na discussão sobre o controle do corpo e comportamento feminino desde a infância. Em seguida, vimos algumas imagens onde tentávamos identificar relações de poder, por exemplo, na escola, na família e nas expressões artísticas. Para finalizar ouvimos duas músicas, Cálice, do Chico Buarque, e Que país é esse?, da Legião Urbana. Só consegui aplicar as músicas em uma das turmas devido ao tempo que foi utilizado para cantar o Hino da Bandeira na primeira aula.

Estas duas breves experiências didáticas expressam algumas de minhas subjetividades e características pessoais, em outros termos, está muito ligada a elementos com os quais me identifico. Ao longo da graduação participei de dois projetos de iniciação científica e um de 
extensão relacionado à temática do patrimônio cultural dos indígenas Guarani Nhandeva no Paraná. Sendo assim, abordar etnicidade e questões indígenas no ano de 2011 tem muito a ver com minha trajetória acadêmica. Por outro lado, trabalhar questões de gênero, sexualidade, política e cotidiano, e utilizar recursos audiovisuais, estão muito ligados às minhas preferências teórico-metodológicas e meus gostos particulares por música e cinema.

\section{Considerações finais}

Ao olhar para o professor, evidencia-se um dos focos que nos possibilita investigar o espaço escolar e esclarecer alguns dos seus aspectos. Olhar para as subjetividades nos ajuda a compreender mais do que particularidades. A partir da figura do professor, e de sujeitos específicos, é possível perceber um espaço complexo, permeado por regras, normas, rituais (cotidianos e extracotidianos), dinâmicas específicas e interações entre diversos atores sociais.

As várias atividades realizadas ao longo desses dois anos de estágio, sobretudo, entrevistas, observação e regência, possibilitou algumas consideração sobre as identidades e performances docentes. Deve-se considerar que a atual conjuntura do ensino de Sociologia no ensino médio configura um campo de constantes disputas e 
negociações. As possibilidades e estratégias de atuação são amplas. Com as entrevistas e a observação é possível perceber alguns caminhos escolhidos por atores sociais específicos. A cultura escolar, as diferentes configurações e as dinâmicas das aulas, não podem ser desconsideradas nesse quadro. Nesse sentido, a atuações dos professores sempre estão combinadas com as dinâmicas particulares dos diversos espaços escolares.

As subjetividades dos atores - professores -, seus gostos, estilos, preferências teórico-metodológicas e temáticas, entre outras características singulares, são diacríticos na construção e efetivação de práticas. Observá-las possibilita compreendermos como os professores desempenham performances específicas e, na relação com o "outro", são arquitetadas identidades professorais, imagens e percepções particulares que conferem sentido à professoralidade, ao ser-estar professor.

\section{Referências}

CARNIEL, F. A invenção (pedagógica) da surdez: sobre a gestão estatal da Educação Especial na primeira década do século XXI. Tese de Doutorado. Programa de Pós-Graduação em Sociologia Política. Universidade Federal de Santa Catarina. Florianópolis, 2013.

DAWSEY, John Cowart. De que riem os "bóias-frias"?: Walter 45 
Benjamin e o teatro épico de Brecht em carrocerias de caminhões. Tese (Livre-Docência)-PPGAS/FFLCH, Universidade de São Paulo, São Paulo, 1999.

. O teatro dos "bóias-frias": repensando a antropologia da performance. Horizontes Antropológicos. Porto Alegre, ano 11, n. 24, p. 15-34, jul./dez. 2005.

FOUCAULT, Michel. Microfísica do poder. Rio de Janeiro, RJ: Graal,1985.

GOFFMAN, Erving. A representação do eu na vida cotidiana. Petrópolis: Vozes, 1985.

GOODSON, I. Trajetória para o currículo: história pessoal e política social em estudos curriculares. In: Educação temática digital. Campinas, v. 9. N. esp. 2008.

JULIA, D. A cultura escolar como objeto histórico. In: Revista Brasileira de História da Educação. Campinas, n. 1, 2001.

MEUCCI, Simone. A institucionalização da sociologia no Brasil: os primeiros manuais e cursos. Dissertação de mestrado. Unicamp, 2000.

PERALVA, A; SPOSITO, M. Quando o sociólogo quer saber o que é ser professor: entrevista com François Dubet. In: Revista brasileira de educação. RJ. N. 5-6, 1997.

PROMUNDO; SALUD Y GENERO; Comunicação em Sexualidade ECOS; Instituto PAPAI; World Education. Era uma vez outra Maria. São Paulo: IPPF, 2006. 1 DVD (20 min), color. Programas: AL, BE, CE, MA, MG, PB, PE, RJ, RN, SC. 
SCHECHNER, Richard. Between Theater and Anthropology. Philadelphia: The University of Pennsylvania Press, 1985.

. O que é Performance? O percevejo: revista de teatro crítica e estética: estudos da performance. Ano 11, n.12, 2003.

Performers e espectadores - transportados e transformados. Moringa. João Pessoa, v. 2, n. 1, jan./jun., 2011, p. 155185.

STANO, R. Sentidos e espaços da professoralidade. In: A identidade do professor no envelhecimento. São Paulo: Cortez, 2001, p. 37-48.

TURNER, Victor. The Anthropology of performance. New York: PAJ Publications, 1987. . Floresta de Símbolos. Rio de Janeiro: EDUFF, 2005.

- Dramas, campos e metáforas: ação simbólica na sociedade humana. Niterói: Editora da Universidade Federal Fluminense, 2008. 